\title{
PENINGKATAN HASIL BELAJAR EKONOMI AKUNTANSI MELALUI PEMBELAJARAN TUTOR SEBAYA PADA SISWA SMA NEGERI 1 KOTO BESAR DHARMASRAYA
}

\author{
Wakini \\ SMA Negeri 1 Koto Besar Dharmasraya, Indonesia \\ Email : wakinikikin759@gmail.com
}

\begin{abstract}
This study aims to 1) describe the application of peer tutoring, learning models in Accounting, Economics subjects, 2) describe student learning outcomes after the application of peer tutoring learning models in Accounting Economics subjects. This type of research is Classroom Action Research (PTK). The learning outcome instrument used was an exercise question that was given at the end of each cycle. This research was conducted at SMA Negeri I Koto Besar Dharmasraya class XII IIS 1 with 13 students, consisting of 5 girls and 8 boys. The results of pre-action research obtained an average value of 65 with $7.6 \%$ classical completeness. Then the increase in the first cycle obtained an average value of 74.6 with $46.1 \%$ complete. The increase continued to occur in the second cycle, it was obtained an average value of 84.6 with classical completeness of $92.3 \%$. This increase occurred because learning with peer tutors made students feel less awkward with each other, more daring to ask questions that had not been understood and there was intensive interaction between teachers and students and students with peer tutors. Based on these results, it can be concluded that the improvement of student learning outcomes can be achieved by implementing peer tutoring learning.
\end{abstract}

Keywords:learning outcomes, economics, peer tutoring

\begin{abstract}
Abstrak:Penelitian ini bertujuan untuk 1) mendeskripsikan penerapan model pembelajaran Tutor Sebaya pada mata pelajaran Ekonomi Akuntansi, 2) mendeskripsikan hasil belajar siswa setelah penerapan model pembelajaran Tutor Sebaya pada mata pelajaran Ekonomi Akuntansi. Jenis penelitian ini adalah Penelitian Tindakan Kelas (PTK). Instrumen hasil belajar yang digunakan adalah soal latihan yang diberikan pada setiap akhir siklus. Penelitian ini dilaksakan di SMA Negeri I Koto Besar Dharmasraya kelas XII IIS 1 dengan jumlah siswa 13 orang, terdiri atas perempuan 5 orang dan laki-laki 8 orang siswa. Hasil penelitian pra tindakan diperoleh rata-rata nilai 65 dengan ketuntasan klasikal 7,6 \%. Kemudian meningkat pada siklus I diperoleh rata-rata nilai 74,6 dengan ketuntasan 46,1\%. Peningkatan terus terjadi pada siklus II diperoleh rata-rata nilai sebesar 84,6 dengan ketuntasan klasikal sebesar 92,3\%. Peningkatan ini terjadi karena belajar bersama Tutor Sebaya membuat siswa tidak canggung satu sama lain, lebih berani untuk bertanya hal yang belum dipahami dan terjadi interaksi intensif baik guru dengan siswa maupun siswa dengan Tutor Sebayanya. Berdasarkan hasil penelitian tersebut dapat disimpulkan bahwa peningkatan hasil belajar siswa dapat dicapai dengan menerapkan pembelajaran Tutor Sebaya.
\end{abstract}

Kata Kunci: Tutor Sebaya,hasilbelajar, ekonomi akuntasi.

\section{PENDAHULUAN}

Pendidikan Nasional bertujuan untuk mengembangkan potensi siswa agar menjadi manusia yang beriman dan bertakwa kepada Tuhan Yang Maha Esa, 
berakhlak mulia, sehat, berilmu, cakap, kreatif, mandiri, dan menjadi warga negara yang demokratis serta bertanggung jawab (Suwartini, 2017). Oleh karena itu dunia pendidikan diharapkan mampu membentuk sumber daya manusia yang terampil, kreatif dan inovatif belandarkan iman dan taqwa. Upaya membentuk sumber daya manusia sesuai dengan tuntutan perkembangan zaman diperlukan penguasaan ilmu pengetahuan dan teknologi salah satunya adalah ekonomi akuntansi. upaya penguasaan materi ekonomi akuntansi dapat dicapai dengan proses pembelajaran yang baik. Proses pembelajaran diharapkan dapat mengembangkan seluruh potensi siswa, baik kognitif, afektif maupun psikomotorik, walaupun saat ini masih didominasi perhatian terhadap aspek kognitif (Haryadi dan Aripin, 2015).

Proses pembelajaran yang baik, hendaknya mampu menjadikan siswa lebih aktif dalam berpartisipasi dengan melibatkan aspek intelektual dan emosional siswa. Ketercapaian tujuan pembelajaran ditentukan oleh pemilihan model yang tepat dan sesuai. Guru sebagai sumber belajar dituntut untuk kreatif dalam menentukan model pembelajaran yang tepat untuk siswa (Nurmala, Sukayasa, dan $P$, 2016). Hal ini menjadi tanggungjawab gurusiswa yang belajar akan mengalami perubahan baik pengetahuan, pemahaman, penalaran, keterampilan, nilai dan sikap. Agar perubahan tersebut dapat tercapai, diperlukan tindakan yang efektif dalam mendorong siswa untuk aktif belajar dan dapat memenuhi kriteria ketuntasan minimal yang telah ditetapkan.

Berdasarkan hasil observasi pra tindakan hasil belajar siswa sebagian besar belum memenuhi kriteria ketuntasan minimal maupun klasikal. Hal ini dibuktikan dengan nilai rata-rata yang diperoleh yaitu sebesar 65 dengan ketuntasan klasikal $7,7 \%$. Kondisi ini disebabkan oleh siswa yang cenderung merasa takut untuk menyampaikan pertanyaan maupun pendapatnya kepada forum kelas. Sehingga siswa lebih berani bertanya atau berpendapat tentang materi pelajaran kepada teman sebangku atau teman lainnya.

Dari data diatas dapat kita simpulkan bahwa rendahnya nilai rata-rata dan rendahnya tingkat ketuntasan siswa menunjukkan bahwa hasil belajar siswa yang juda rendah. Sehingga diperlukan upaya kongkrit untuk menyelesaikan masalah pembelajaran. Salah model pembelajaran yang tepat untuk mengatasi permasalahan ini adalah model pembelajaran tutor sebaya. 
Model pembelajaran tutor sebaya (peergroup) adalah model yang memotivasi siswa dalam belajar bekerja sama (kooperatif), saling memberi semangat dan membantu rekannya yang kesulitan dalam menuntaskan keterampilan-keterampilan yang dipersentasikan oleh guru dan meningkatkan hubungan social antar siswa (Ahdiyat, 2014). Model pembelajaran tutor sebaya memberikan kesempatan kepada siswa untuk aktif berlajar, dengan teman sebaya tanpa ada rasa canggung untuk saling berpendapat bertanya dan menyelesaaikan masalah bersama(Mahsup et al., 2020). Dengan model pembelajaran Tutor Sebaya siswa yang yang bertugas menjadi tutor mendapat manfaat ganda yaitu mempelajari dan memahami materi yang diberikan sekaligus membantu teman sejawat untuk dapat juga memahami materi (Anggorowati, 2013). Siswa yang belajar kepada teman sejawatnya tidak akan merasa canggung dan kaku, karena sudah terbiasa berinteraksi bersama di sekolah. Pembelajaran akan berjalan menyenangkan dan interaktif karena siswa tidak lagi merasa takut untuk bertanya atau berpendapat kepada teman sejawat.

Menurut Nurmala et al. (2016) tutor sebaya tidak segan membantu temannya yang sedang kesulitan dalam memahami materi, sehingga teman yang dibantu terus termotivasi untuk belajar dan berpengaruh pada hasil belajar yang terus meningkat. Sejalan dengan itu Ramadhani dan Kartiko (2018) menyampaikan bahwa model pembelajaran Tutor Sebaya dapat meningkatkan hasil belajar siswa, membuat siswa lebih aktif dan bertanggungjawab. Beberapa manfaat dari pembelajaran dengan metode tutor sebaya, antara lain; 1) hasilnya lebih baik bagi beberapa anak yang memiliki perasaan takut atau enggan kepada guru, 2) bagi tutor, dapat memberikan kesempatan untuk menelaah kembali secara mendalam dan melatih diri untuk mengemban tanggung jawab dan kesabaran, 3) mempererat hubungan sosial antara siswa (Djamarah dan Zain, 2015). Adapun langkah-langkah metode tutor sebaya yang siap diimplementasikan adalah: 1) Guru menentukan tutor dengan mengacu pada nilai akademik siswa, memilih siswa dengan daya serap tinggi. 2) Guru membagi kelompok sesuai dengan jumlah tutor, 3) Guru memberi arahan terkait tugas dan tanggung jawab tutor, 4) Guru memberikan pelatihan kepada tutor hingga tutor memahami materi yang akan dibagikan kepada teman sejawatnya, 5) Guru menyampaikan tujuan pembelajaran kepada seluruh siswa 
secara tuntas dan jelas. 6) Guru memastikan bahwa seluruh siswa sudah duduk berdasarkan kelompok, 7) Guru menjelaskannya materi pembelajaran kepada seluruh siswa, baik tutor maupun tutee (siswa), 8) Guru memberikan tugas kepada tutee, tutor membantu tutee yang mengalami kesulitan, 9) Guru menghampiri setiap kelompok, mengamati dan membantu jika ada kelompok yang mengalami kesulitan mengerjakan soal atau materi pembelajaran, 10) Guru memberikan tes individu untuk mengukur kemampuan siswa, 11) Guru mengadakan evaluas bersama bersama tutor dan tutee mendapatkan masukan tentang kendala yang harus diperbaiki pada pembelajaran berikutnya(Munthe dan Naibaho, 2019).

Oleh karena itu, peneliti tertarik melakukan penelitian terkait penerapan metode pembelajaran tutor sebaya untuk meningkatkan hasil belajar ekonomi akuntansi pada siswa kelas XII IIS 1 SMA Negeri I Koto Besar Dharmasraya. Adapun tujuan Penelitian tindakan kelas ini dilakukan adalah untuk 1) mengetahui bagaimana penerapan model pembelajaran tutor sebaya, 2) mengetahui bagaimana penerapan model pembelajaran tutor sebaya dapat meningkatkan hasil belajar ekonomi akuntansi pada Siswa Kelas XII IIS 1 SMA Negeri I Koto Besar Dharmasraya.

\section{METODE}

Jenis penelitian ini adalah Penelitian Tindakan Kelas (PTK). Kusumah dan Dwitagama, (2012) menyatakan bahwa penelitian tindakan kelas adalah penelitian yang dilakukan oleh guru di kelasnya sendiri dengan cara merencanakan, melaksanakan, dan merefleksi tindakan secara kolaboratif dan partisipasif dengan tujuan memperbaiki kinerjanya sebagai guru, sehingga hasil belajar siswa dapat meningkat. Penelitian ini dilakukan secara kolaboratif antara guru SMA Negeri 1 Koto Besar dengan peneliti. Guru bertindak sebagai pelaksana pembelajaran, sedangkan peneliti bertindak sebagai observer.

Subjek dalam penelitian ini adalah siswa kelas XII IIS 1 yang berjumlah 13 siswa, terdiri atas perempuan 5 orang dan laki-laki 8 orang siswa. Dari jumlah tersebut memiliki latar belakang pendidikan orang tua siswa, prestasi akademik, status ekonomi yang heterogen. Tempat penelitian ini dilaksakan di SMA Negeri I Koto Besar Dharmasraya kelas XII IIS. Sumber data primer diperoleh dari nilai 
latihan sesudah pembelajaran berakhir. Data dari pengamatan teman sejawat atau kolaboratorator termasuk data sekunder. Sumber data sekunder diperoleh dari hasil pengamatan yang dilakukan kolaborator. Dilihat dari bentuk data, Data pengamatan merupakan data kualitatif dan dari nilai latihan sesudah pembelajaran berakhir merupakan data kuantitatif.

Teknik pengumpulan dan analisa data pada penelitian ini digunakan untuk mencari data kondisi awal hasil belajar ekonomi akuntansi. Jawaban soal tes setiap siklus digunakan untuk memperoleh data hasil belajar ekonomi akuntansi pada siklus I dan II. Teknik analisis data menggunakan deskripsi komparatif yang diteruskan dengan refleksi. Deskripsi komparatif dilakukan dengan membandingkan hasil belajar siswa pada kondisi awal, siklus Idan siklus II. Kemudian dilakukan refleksi untuk menarik kesimpulan dan menentukan rencana tindak lanjut.

\section{HASIL DAN PEMBAHASAN}

\section{Hasil}

Penelitian tindakan kelas ini dilakukan dengan metode pembelajaran tutor sebaya pada mata pelajaran ekonomi akuntansi. Penelitian ini terdiri dari 2 siklus. data siklus I pada kompetensi dasar mengidentifikasi jurnal khusus dan jurnal umum, berlangsung 4 kali pertemuan. Pertemuan ke 1 pada indikator pencapaian kompetensi jurnal penerimaan kas dan jurnal pengeluaran kas, pertemuan ke 2 diskusi jurnal penerimaan kas dan jurnal pengeluaran kas . pertemuan ke 3 pada indikator pencapaian kompetensi jurnal pembelian, jurnal penjualan dan jurnal umum, pertemuan ke 4 diskusi jurnal pembelian, jurnal penjualan dan jurnal umum. sedangkan data siklus 2 pada kompetensi dasar mengidentifikasi buku besar utama dan buku besar pembantu, berlangsung 2 kali pertemuan. Pertemuan ke 1 pada indikator pencapaian kompetensi buku besar utama dan buku besar pembantu, pertemuan ke 2 diskusi buku besar utama dan buku besar pembantu.

Siklus I berlangsung 4 kali pertemuan, siklus II berlangsung 2 kali pertemuan. Untuk variabel yang diteliti adalah penggunaan metode pembelajaran Tutor Sebaya dalam meningkatkan hasil belajar ekonomi siswa. Langkah-langkah dalam setiap siklus terdiri dari : (1) Perencanaan, meliputi pembuatan skenario 
pembelajaran dan format-format yang dibutuhkan. (2) Pelaksanaan, yaitu pelaksanaan skenario pembelajaran yang telah disiapkan. Observasi/pengamatan, yaitu kegiatan pengamatan yang dilakukan oleh guru kolaborasi bersama peneliti terhadap hasil belajar ekonomi siswa secara perorangan pada setiap pertemuan.Instrumen yang digunakan adalah ujian singkat setiap akhir pertemuan. (4) Refleksi, yaitu kegiatan menganalisa dan mengolah data untuk meninjau keberhasilan dari tindakan, serta kendala-kendala yang ditemukan dan untuk merencanakan tindakan selanjutnya.

Persiapan yang dilakukan dalam penelitian tindakan kelas ini meliputi : (1) Perangkat pembelajaran berupa program tahunan, program semester dan rencana proses pembelajaran.(2) Menyusun jadwal penelitian(3) Menyiapkan soal tes tiap siklus, (4) Membuat lembaran cacatan untuk guru.Tahapan penelitian yang telah dilaksanakan adalah 1) guru mengidentifikasi beberapa peserta didik yang memiliki, guru mengidentifikasi beberapa kemampuan untuk menjadi tutor, 2) guru melatih tutor dalam materi yang akan dipelajari dalam kelas dan menjelaskan latihan serta evaluasi yang akan dipelajari dalam kelas dan menjelaskan latihan serta evaluasi yang akan dilakukan, 3) guru menjelaskan materi pelajaran kepada semua siswa dan memberi peluang tanya jawab apabila terdapat materi yang belum jelas, 4) tutor sejawat membantu temannya dalam mengerjakan tugas dan memberikan tutor sejawat membantu temannya dalam mengerjakan tugas dan memberikan penjelasan tentang materi yang belum dipahami oleh temannya dalam satu penjelasan tentang materi yang belum dipahami oleh temannya dalam satu kelompok, 5) guru mengamati aktivitas tutoring, 6) guru mengevaluasi materi kelompok, 7) guru, tutor, dan peserta didik memberikan evaluasi proses belajarmengajar.

Kondisi pra tindakan siswa cenderung pasif kurang termotivasi di dalam belajar. Hal ini ditandai dengan banyaknya siswa yang tidak mengerjakan tugas dengan alasan mereka mengatakan tidak bisa, tidak memahami apa yang diterangkan oleh guru, ada juga sebagian siswa yang mengantuk, mengobrol dengan teman yang duduk di sampingnya atau bahkan yang ada di depan atau di belakang tempat duduknya. Demikian juga bila pembelajaran dilakukan dengan diskusi mereka cenderung diam, pasif, dan tidak mau berpikir sama sekali. 
Berdasarkan hasil pengamatan diperoleh hasil belajar ekonomi pada pra siklus seperti yang tersaji dalam tabel berikut.

Tabel 1 Hasil Belajar Siswa Pra Siklus

\begin{tabular}{clccc}
\hline No. & \multicolumn{1}{c}{ Nama } & Jenis Kelamin & Nilai & Keterangan \\
\hline $\mathbf{1}$ & Aldiansyah & $\mathrm{L}$ & 70 & tidak tuntas \\
\hline $\mathbf{2}$ & Anisa & $\mathrm{P}$ & 70 & tidak tuntas \\
\hline $\mathbf{3}$ & Bregi Saputra & $\mathrm{L}$ & 60 & tidak tuntas \\
\hline $\mathbf{4}$ & Gustina & $\mathrm{P}$ & 65 & tidak tuntas \\
\hline $\mathbf{5}$ & Ilman febriandi & $\mathrm{L}$ & 70 & tidak tuntas \\
\hline $\mathbf{6}$ & Indah Lenggo Geni & $\mathrm{P}$ & 50 & tidak tuntas \\
\hline $\mathbf{7}$ & Loli Gusriani & $\mathrm{P}$ & 80 & tuntas \\
\hline $\mathbf{8}$ & M Fauzan & $\mathrm{L}$ & 60 & tidak tuntas \\
\hline $\mathbf{9}$ & Ogim Junandi & $\mathrm{L}$ & 60 & tidak tuntas \\
\hline $\mathbf{1 0}$ & Rahmat Hidayat & $\mathrm{L}$ & 60 & tidak tuntas \\
\hline $\mathbf{1 1}$ & Sonya Senja Abjana & $\mathrm{P}$ & 60 & tidak tuntas \\
\hline $\mathbf{1 2}$ & Tomi Sugara & $\mathrm{L}$ & 70 & tidak tuntas \\
\hline $\mathbf{1 3}$ & Tori Afrianto & $\mathrm{L}$ & 70 & tidak tuntas \\
\hline \multicolumn{5}{c}{ Rata-Rata Nilai } \\
\hline \multicolumn{5}{c}{ Jumlah siswa tuntas sebanyak 1 orang atau 7,7 \% } \\
\hline
\end{tabular}

Dari tabel diatas diketahui bahwa rata-rata hasil belajar siswa 65, dimana hal ini belum memenuhi kriteria yang ditergetkan yaitu sebesar 80. Dari aspek ketuntasan klasikal siswa yang telah mencapai ketuntasan klasikal hanya 1 orang atau 7,6\%, dimana hal ini belum memenuhi target kinerja ketuntasan klasikal yaitu $80 \%$. Penyebabnya adalah kurangnya semangat siswa dalam belajar ditandai oleh kurang antusias siswa pada saat mengikuti pembelajaran, seperti kurangnya keinginan siswa untuk bertanya atau memberi tanggapan pada saat mengikuti pembelajaran. Demikian juga berdasarkan pengamatan konsentrasi siswa kurang dalam mengikuti pembelajaran. Pada saat guru menjelaskan materi pelajaran masih dijumpai siswa yang kurang memperhatikan, mereka berbincang-bincang sendiri dengan teman yang ada di sampingnya atau bahkan yang ada di belakang maupun yang ada di depan tempat duduknya. Sehingga berimplikasi pada hasil belajar siswa yang rendah.

Pada siklus I, guru menyusun rencana pelaksanaan pembelajaran dan menyiapkan instrumen penelitian. Siklus I terdiri dari 4 pertemuan, dimana setiap pertemuannya disampaikan materi yang berbeda dengan langkah sebagai berikut: 


\section{Apersepsi}

a. Guru mempersiapkan belajar siswa dengan berdoa dan mengabsen siswa.

b. Guru menyampaikan tujuan pembelajaran yang ingin dicapai

c. Guru memberikan pertanyaan awal tentang materi pengertian jurnal khusus dan jurnal umum.

Kegiatan Inti yang terdiri dari:

2. Eksplorasi

a. Guru menyajikan materi tentang jurnal khusus dan jurnal umum

b. Siswa diberi kesempatan untuk menanyakan materi yang belum dipahami

c. Guru mengorganisasikan siswa dalam 4 kelompok yang tiap-tiap kelompok terdiri dari 3-4 orang siswa, dalam tiap kelompok terdapat satu siswa yang bertindak sebagai tutor dan ketua kelompok. Pembagian kelompok sebagai berikut; kelompok 1; jurnal penerimaan kas, kelompok 2; jurnal penerimaan kas, kelompok 3 : jurnal pengeluaran kas, kelompok 4; jurnal pengeluaran kas.

3. Elaborasi

a. Guru meminta setiap tutor dari setiap kelompok maju kedepan kelas untuk mendaptkan penjelasan materi dan petunjuk, serta arahan dari guru. Tujuannya agar tutor dapat membantu memberikan penjelasan kepada temannya dalam kelompok pada saat mengerjakan soal-soal diskusi.

b. Guru membagi soal yang akandidiskusikan kemasing-masing Tutor Sebaya untuk dibahas dan dikerjakan kelompok belajarnya masingmasing

c. Siswa mengerjakan soal yang diberikan guru untuk didiskusikan dengan bantuan tutor sebaya

d. Guru mengawasi jalannya tutorial dengan baik dan memberikan penilaian proses

e. Guru memberitahukan bahwa waktu yang diberikan untuk kegiatan tutorial berakhir. Kolaboratorator mengamati kegiatan guru dan siswa 
selama proses pembelajaran dengan menggunakan instrumen pengamatan yang telah dipersiapkan sebelumnya.

4. Konfirmasi

a. Guru memberikan umpan balik positif secara lisan maupun tulisan terhadap keberhasilan siswa dalam mengikuti pembelajaran.

b. Guru memberikan konfirmasi terhadap hasil eksplorasi dan elaborasi.

5. Penutup

a. Guru bersama-sama dengan siswa membuat rangkuman / simpulan pelajaran.

b. Guru menginformasikan soal latihan tersebut diharapkan dapat dipresentasikan pada pertemuan berikutnya.

c. Menutup pelajaran dengan membaca hamdalah.

Pada siklus I pembelajaran sudah menggunakan metode tutor sebaya. Namun pembelajaran masih berjalan kurang maksimal karena masih banyak siswa yang kurang termotivasi dalam belajar ekonomi akuntansi karena banyak siswa yang tidak ikut serta memberikan tanggapan maupun mengajukan pertanyaan. Pada saat mengerjakan latihan masih banyak siswa yang belum melaksanakan tugas dengan baik, mereka cenderung diam melihat temannya yang terlihat sungguh-sungguh dalam mengerjakan tugas. Walaupun dari aspek ketuntasan individual dan klasikal terus meningkat. Hal ini dapat diamati pada tabel berikut:

Tabel 2 Hasil Belajar Siswa Siklus I

\begin{tabular}{clccc}
\hline No. & \multicolumn{1}{c}{ Nama } & $\begin{array}{c}\text { Jenis } \\
\text { Kelamin }\end{array}$ & Nilai & Keterangan \\
\hline $\mathbf{1}$ & Aldiansyah & $\mathrm{L}$ & 80 & tuntas \\
\hline $\mathbf{2}$ & Anisa & $\mathrm{P}$ & 80 & tuntas \\
\hline $\mathbf{3}$ & Bregi Saputra & $\mathrm{L}$ & 70 & tidak tuntas \\
\hline $\mathbf{4}$ & Gustina & $\mathrm{P}$ & 70 & tidak tuntas \\
\hline $\mathbf{5}$ & Ilman febriandi & $\mathrm{L}$ & 80 & tuntas \\
\hline $\mathbf{6}$ & Indah Lenggo Geni & $\mathrm{P}$ & 60 & tidak tuntas \\
\hline $\mathbf{7}$ & Loli Gusriani & $\mathrm{P}$ & 80 & tuntas \\
\hline $\mathbf{8}$ & M Fauzan & $\mathrm{L}$ & 70 & tidak tuntas \\
\hline $\mathbf{9}$ & Ogim Junandi & $\mathrm{L}$ & 80 & tuntas \\
\hline $\mathbf{1 0}$ & Rahmat Hidayat & $\mathrm{L}$ & 80 & tuntas \\
\hline $\mathbf{1 1}$ & Sonya Senja & $\mathrm{P}$ & 70 & tidak tuntas \\
& Abjana & & & \\
\hline
\end{tabular}




\begin{tabular}{rllcc}
\hline $\mathbf{1 2}$ & Tomi Sugara & L & 70 & tidak tuntas \\
\hline $\mathbf{1 3}$ & Tori Afrianto & L & 80 & tuntas \\
\hline \multicolumn{5}{c}{ Rata-Rata Nilai } \\
\hline
\end{tabular}

Berdasarkan Tabel 2 dapat diketahui hasil belajar siklus 1 diperoleh rata-rata nilai 74,6 dengan jumlah siswa yang tuntas sebanyak 7 orang atau 53\%. Dari hasil tersebut dapat dilihat bahwa hasil belajar siswa sudah meningkat dibandingkan dengan prasiklus, dari rata-rata nilai sebesar 65 menjadi 74,6. Dari aspek kentuntasan klasikal juga meningkat dari 1 orang atau 7,7\% menjadi 7 orang 53,8 $\%$. Sehingga masih diperlukan siklus lanjutan untuk mencapai target nilai rata-rata kelas yaotu $80 \%$ dan target ketuntasan klasikal sebesar $80 \%$.

Dari hasil refleksi akhir siklus I, belum tercapainya terget nilai rata-rata dan ketuntasan klasikal disebabkan oleh beberapa hal yaitu; a) guru belum optimal dalam membangkitkan motivasi siswa untuk mengikuti pembelajaran, b) guru kurang jelas dan tegas dalam menyampaikan materi, c) siswa kurang memperhatikan guru pada saat guru menjelaskan materi.Sehingga perlu dilakukan perbaikan sesuai hasil refleksi dengan tujuan untuk meningkatkan hasil belajar siswa pada siklus II.

Pelaksanaan siklus II, terdiri dari perencanaan dimana guru menyusun rencana pelaksanaan pembelajaran atas dasar refleksi siklus pertama dan menyiapkan instrumen penelitian. Pelaksanan tindakan kelas pada siklus kedua ini terdiri dari dua pertemuan. Dari hasil pelaksanaan siklus II didapatkan data hasil belajar siswa sebagai berikut:

Hasil Pengamatan pada siklus II pembelajaran masih menggunakan metode pembelajaran tutor sebaya penelitian tindakan kelas ini dilakukan dengan metode pembelajaran tutor sebaya pada mata pelajaran ekonomi akuntansi. Siklus 2 pada kompetensi dasar mengidentifikasi buku besar utama dan buku besar pembantu, berlangsung 2 kali pertemuan. Pertemuan ke 1 pada indikator pencapaian kompetensi buku besar utama dan buku besar pembantu, pertemuan ke 2 diskusi buku besar utama dan buku besar pembantu. Pembelajaran berjalan sudah lumayan lancar, sebagian siswa mulai termotivasi dalam belajar ekonomi akuntansi terlihat banyak siswa mulai belajar mengerjakan latihan yang guru berikan dengan baik. 
Tabel 3 Hasil Belajar Siswa siklus II

\begin{tabular}{clccc}
\hline No. & \multicolumn{1}{c}{ Nama } & Jenis Kelamin & Nilai & Keterangan \\
\hline $\mathbf{1}$ & Aldiansyah & $\mathrm{L}$ & 90 & tuntas \\
\hline $\mathbf{2}$ & Anisa & $\mathrm{P}$ & 90 & tuntas \\
\hline $\mathbf{3}$ & Bregi Saputra & $\mathrm{L}$ & 80 & tuntas \\
\hline $\mathbf{4}$ & Gustina & $\mathrm{P}$ & 90 & tuntas \\
\hline $\mathbf{5}$ & Ilman febriandi & $\mathrm{L}$ & 80 & tuntas \\
\hline $\mathbf{6}$ & Indah Lenggo Geni & $\mathrm{P}$ & 80 & tuntas \\
\hline $\mathbf{7}$ & Loli Gusriani & $\mathrm{P}$ & 100 & tuntas \\
\hline $\mathbf{8}$ & M Fauzan & $\mathrm{L}$ & 80 & tuntas \\
\hline $\mathbf{9}$ & Ogim Junandi & $\mathrm{L}$ & 70 & tidak tuntas \\
\hline $\mathbf{1 0}$ & Rahmat Hidayat & $\mathrm{L}$ & 90 & tuntas \\
\hline $\mathbf{1 1}$ & Sonya Senja Abjana & $\mathrm{P}$ & 80 & tuntas \\
\hline $\mathbf{1 2}$ & Tomi Sugara & $\mathrm{L}$ & 80 & tuntas \\
\hline $\mathbf{1 3}$ & Tori Afrianto & $\mathrm{L}$ & 90 & tuntas \\
\hline \multicolumn{2}{c}{ Rata-Rata Nilai } & & $\mathbf{8 4 , 6}$ & \\
\hline & Jumlah siswa tuntas sebanyak $\mathbf{1 2}$ orang atau & $\mathbf{9 2 , 3}$ & \%
\end{tabular}

Berdasarkan Tabel 3 dapat diketahui hasil belajar siklus II diperolehrata-rata nilai 84,6 dengan jumlah siswa yang tuntas sebanyak 12 orang atau 92,3\%. Dari hasil tersebut dapat dilihat bahwa hasil belajar siswa sudah jauh meningkat dibandingkan dengan prasiklus dan siklus II, dari rata-rata nilai pra siklus sebesar 65 menjadi 74,6 pada siklus I dan kemudian mencapai nilai rata-rata 84,6 pada siklus II. Dari aspek kentuntasan klasikal juga jauh meningkat dari pra siklus dan siklus 1 yaitu 1 orang atau 7,7\% pada pra siklus kemudian meningkat menjadi menjadi 7 orang atau 53,8 \%, selanjutnya jauh meningkat menjadi 12 orang atau 92,3\% pada siklus II. Dari hasil belajar siklus II target nilai rata-rata kelas minimal dan target ketuntasan klasikal sudah tercapai.

\section{Pembahasan}

Dari hasil penelitian ditemukan bahwa hasil belajar siswa terus meningkat dari pra tindakan sampai pada siklus ke II. Pada aspek ketuntasan klasikal juga terus meningkat dari pra tindakan hanya 1 siswa yang tuntas, menjadi 12 siswa pada siklus II. Hasil ini menunjukkan bahwa penerapan model pembelajaran Tutor Sebaya dapat meningkatkan hasil belajar siswa. Sebagaimana Ahdiyat (2014) menyampaikan bahwa pada penerapan model pembelajaran Tutor Sebaya mampu membuat siswa saling memberi semangat dan motivasi satu sama lain sehingga setiap siswa menjadi semangat belajar dan berpengaruh pada peningkatan hasil belajar yang baik. Pada proses pembelajaran siswa dapat lebih leluasa bertanya 
kepada tutor yang merupakan teman sekelas, tanpa rasa takut atau canggung karena sudah terbiasa berkomunikasi dan berinteraksi di sekolah (Mahsup et al., 2020). Sebagaimana Idris et al. (2017) menyampaikan bahwa guru menunjuk siswa yang memiliki daya serap tinggi bertindak sebagai tutor (pengajar), sehingga siswa yang diberi bantuan tidak merasa enggan atau malu untuk bertanya.

Menurut Hastari (2019) pembelajaran tutor teman sebaya ini akanmeningkatkan tingkat pemahaman mahasiswa terhadap tugas belajar yang diberikan. Hal ini terlihat dari waktu belajar yang digunakan pada kelompok perlakuan. Mereka selesai tepat waktu dan penyelesaian tugas lebih cepat dibandingkan kelompok kontrol dengan model pembelajaran konvensional.Sejalan dengan Abrianto (2019) menyampaikan bahwa pembelajaran Tutor Sebaya memberi kesempatan kepada peserta didik untuk saling berinteraksi dalam proses belajar. Selain itu, pembelajaran ini dapat menerapkan prinsip belajar dari berbagai sumber dan siswa dapat berperan sebagai "guru” bagi teman lainnya.

Menurut Munthe dan Naibaho (2019) ada terdapat beberapa manfaat yang diperoleh pada penerapan model pembelajaran Tutor Sebaya, yaitu: 1) siswa bisa mengungkapkan apa yang menjadi kesulitan belajarnya langsung kepada tutor tanpa harus malu atau takut, 2) siswa dapat saling berdiskusi untuk memberikan pendapat yang di fasilitasi oleh tutor, 3) siswa dapat belajar untuk saling memahami tentang sifat atau karakter siswa lainnya yang ada dalam kelompok, 4) siswa lebih mudah memahami materi, karena komunikasi yang akrab antar teman sebaya, 5) siswa yang berperan sebagai tutor, berkesempatan untuk belajar memimpin dan mendampingi teman sebaya dalam diskusi kelompok, 5) siswa memiliki keleluasaan untuk mengutarakan ide dan pendapat, tanpa harus bergantung penuh pada tutor, 6) siswa yang berperan sebagai tutor, mampu mengambil keputusan secara mandiri, jika terjadi perbedaan pendapat diantara siswa, 7) suasana pembelajaran menjadi santai dan nyaman, karena siswa dapat berkomunikasi dengan teman sebaya tanpa ada rasa canggung dan sungkan.

\section{SIMPULAN}

Dari hasil penelitian dapat disimpulkan bahwa penerapan model pembelajara tutor sebaya dapat meningkatkan hasil belajar siswa. Hal ini disebabkan karena siswa termotivasi untuk belajar karena dibantu dan didampingi 
oleh teman sebaya. Siswa tidak canggung untuk bertanya atau menyampaikan pendapat dalam diskusi kelompok karena yang bertindak sebagai "guru" adalah teman sebaya. Sehingga siswa semangat belajar dan terdorong untuk memahami materi dengan baik yang berdampak pada peningkatan hasil belajar siswa.

\section{DAFTAR RUJUKAN}

Abrianto, O. R. (2019). Penerapan Metode Tutor Sebaya Untuk Meningkatkan

Hasil Belajar Dan Motivasi Belajar Siswa Pada Materi Trigonometri Kelas Xi Mipa 4 Sma Negeri 1 Ambarawa. Satya Widya, 35(1), 62-74. https://doi.org/10.24246/j.sw.2019.v35.i1.p62-74

Ahdiyat, M. (2014). 234958-Metode-Tutor-Sebaya-Untuk-Meningkatkan-H3Be3a61B. Jurnal Formatif, 4(1), 71-79. https://doi.org/http://dx.doi.org/10.30998/formatif.v4i1.141

Anggorowati, N. P. (2013). Penerapan Model Pembelajaran Tutor Sebaya Pada

Mata Pelajaran Sosiologi. KOMUNITAS: International Journal of Indonesian Society and Culture, 3(1), 103-120. https://doi.org/10.15294/komunitas.v3i1.2303

Djamarah, S. B., dan Zain, A. (2015). Strategi Belajar Mengajar. Jakarta: Rineka Cipta.

Haryadi, T., dan Aripin. (2015). Melatih Kecerdasan Kognitif, Afektif, dan

Psikomotorik Anak Sekolah Dasar Melalui Perancangan Game Simulasi "Warungku." ANDHARUPA: Jurnal Desain Komunikasi Visual dan Multimedia, 1(02), 122-133. https://doi.org/10.33633/andharupa.v1i02.963

Hastari, R. C. (2019). Penerapan Strategi Tutor Sebaya Dalam Meningkatkan Motivasi Belajar Matematika. Jurnal Pengabdian Kepada Masyarakat, 4(1). https://doi.org/10.26905/abdimas.v4i1.2811

Idris, R. P., Widiastuti, I., dan Wardani, N. S. (2017). Penerapan Pembelajaran Model Tutor Sebaya ( Peer Tutoring ) Untuk Meningkatkan Keaktifan Dan Prestasi Belajar Siswa Dalam Mata Pelajaran Mekanika Teknik Kelas X. Seminar Nasional Pendidikan Vokasi Ke 2, 2, 356-361.

Kusumah, W., dan Dwitagama, D. (2012). Mengenal Penelitian Tindakan Kelas (2nd ed.). Jakarta: PT Indeks.

Mahsup, M., Ibrahim, I., Muhardini, S., Nurjannah, N., dan Fitriani, E. (2020). 
Peningkatan Hasil Belajar Mahasiswa Melalui Model Pembelajaran Tutor Sebaya. Jurnal Kependidikan: Jurnal Hasil Penelitian Dan Kajian Kepustakaan Di Bidang Pendidikan, Pengajaran Dan Pembelajaran, 6(3), 609. https://doi.org/10.33394/jk.v6i3.2673

Munthe, A. P., dan Naibaho, H. P. (2019). Manfaat dan Kendala Penerapan Tutor Sebaya untuk Siswa Kelas IV Sekolah Dasar Lentera Harapan Mamit. Scholaria: Jurnal Pendidikan Dan Kebudayaan, 9(2), 138-147. https://doi.org/10.24246/j.js.2019.v9.i2.p138-147

Nurmala, Sukayasa, dan P, B. (2016). Penerapan Model Pembelajaran Tutor Sebaya untuk Meningkatkan Hasil Belajar siswa kelas V SDN 20 Toli-Toli pada Operasi Hitung Campuran Bilangan Bulat. Jurnal Kreatif Tadulako Online, 4(9), 199-211.

Ramadhani, A., dan Kartiko, D. C. (2018). Pengaruh Penerapan Metode Pembelajaran Tutor Sebaya Terhadap Hasil Belajar Chest Pass Bola Basket. Jurnal Pendidikan Olahraga Dan Kesehatan, 6(2), 179-183. https://doi.org/https://dx.doi.org/10.26418/jpmipa.v9i2.26773

Suwartini, S. (2017). Pendidikan Karakter dan Pembangunan Sumber Daya Manusia Keberlanjutan. Trihayu: Jurnal Pendidikan Ke SD An, 4(1), 220-234. Retrieved from https://media.neliti.com/media/publications/259090pendidikan-karakter-dan-pembangunan-sumb-e0cf1b5a.pdf 